\title{
Global Medical Device Nomenclature
}

National Cancer Institute

\section{Source}

National Cancer Institute. Global Medical Device Nomenclature. NCI Thesaurus. Code C154416.

A system of internationally agreed generic descriptors used to identify all medical device products. 